\title{
Climate controls on water chemistry states and dynamics in rivers across Australia
}

\author{
Anna Lintern ${ }^{1}$, Shuci Liu ${ }^{2}$, Camille Minaudo ${ }^{3}$, Rémi Dupas ${ }^{4}$, Danlu Guo $^{5}$, kefeng zhang ${ }^{6}$,
} Ulrike Bende-Michl ${ }^{7}$, and Clément Duvert ${ }^{8}$

${ }^{1}$ Monash University

${ }^{2}$ The University of Melbourne Department of Infrastructure Engineering ${ }^{3} \mathrm{EPFL}$

${ }^{4}$ Institut National de Recherche pour l'Agriculture l'Alimentation et l'Environnement

${ }^{5}$ University of Melbourne

${ }^{6}$ University of New South Wales

${ }^{7}$ Australian Bureau of Meteorology

${ }^{8}$ Charles Darwin University

May 28, 2021

\begin{abstract}
We need to understand spatial variability in the mean concentrations and dynamics of riverine water quality for effective water quality management. Using river chemistry data for up to 578 locations across the Australian continent, we assessed the impact of climate zones on (i) interannual mean concentration and (ii) river chemistry dynamics as represented by constituent export regimes (ratio of the coefficients of variation of concentration and discharge) and export patterns (slope of the concentrationdischarge relationship). We found that interannual mean concentrations vary significantly by climate zones. However, export regimes and patterns are generally consistent across climate zones. This suggests that intrinsic properties of individual constituents rather than catchment properties determine export regimes and patterns. The spatially consistent river chemistry dynamics highlights the potential to predict riverine water quality across the Australian continent, which will support national riverine water quality management.
\end{abstract}

Hosted file

ClimateControls_StatesDynamics_HP.docx available at https://authorea.com/users/416256/ articles/523894-climate-controls-on-water-chemistry-states-and-dynamics-in-riversacross-australia 

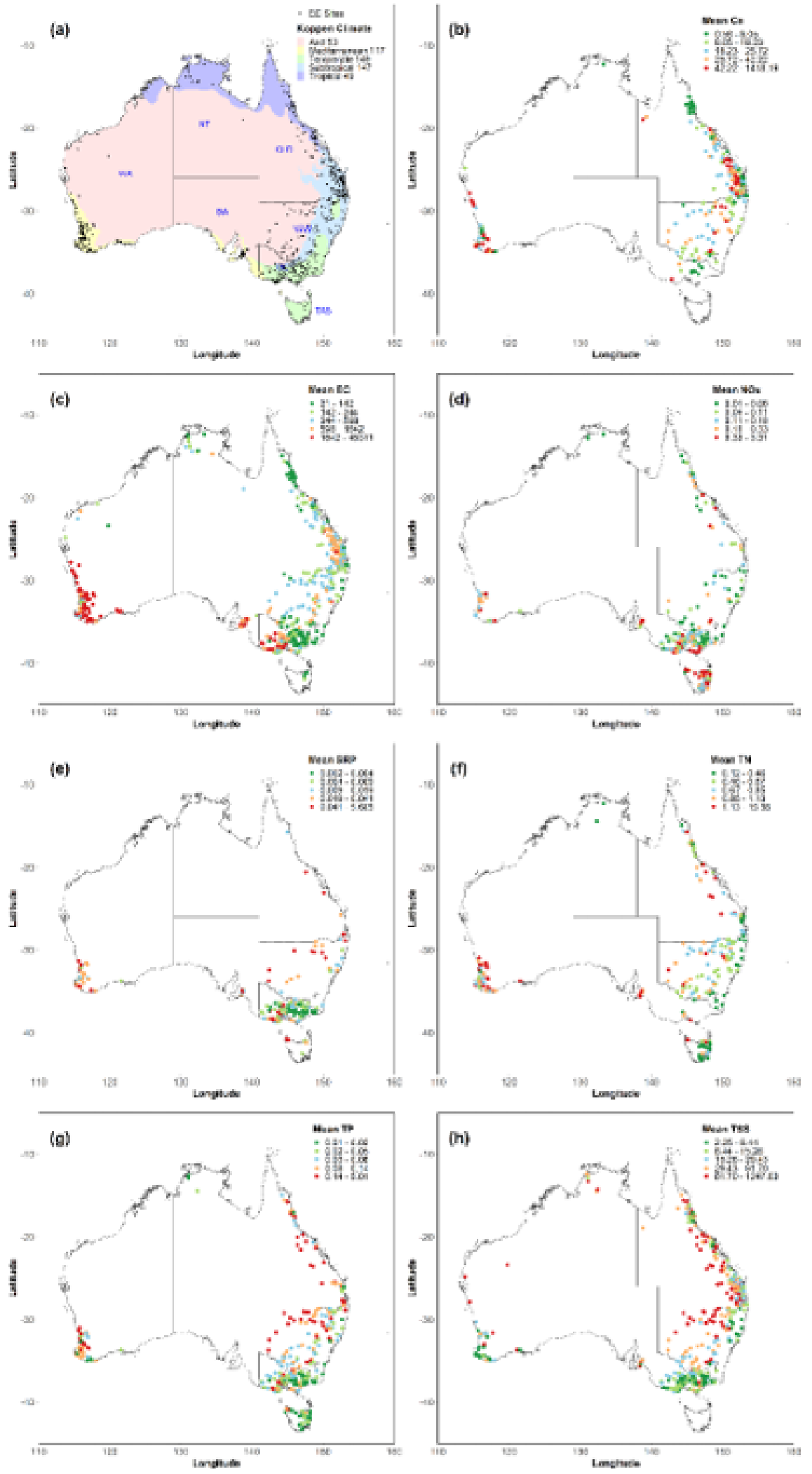

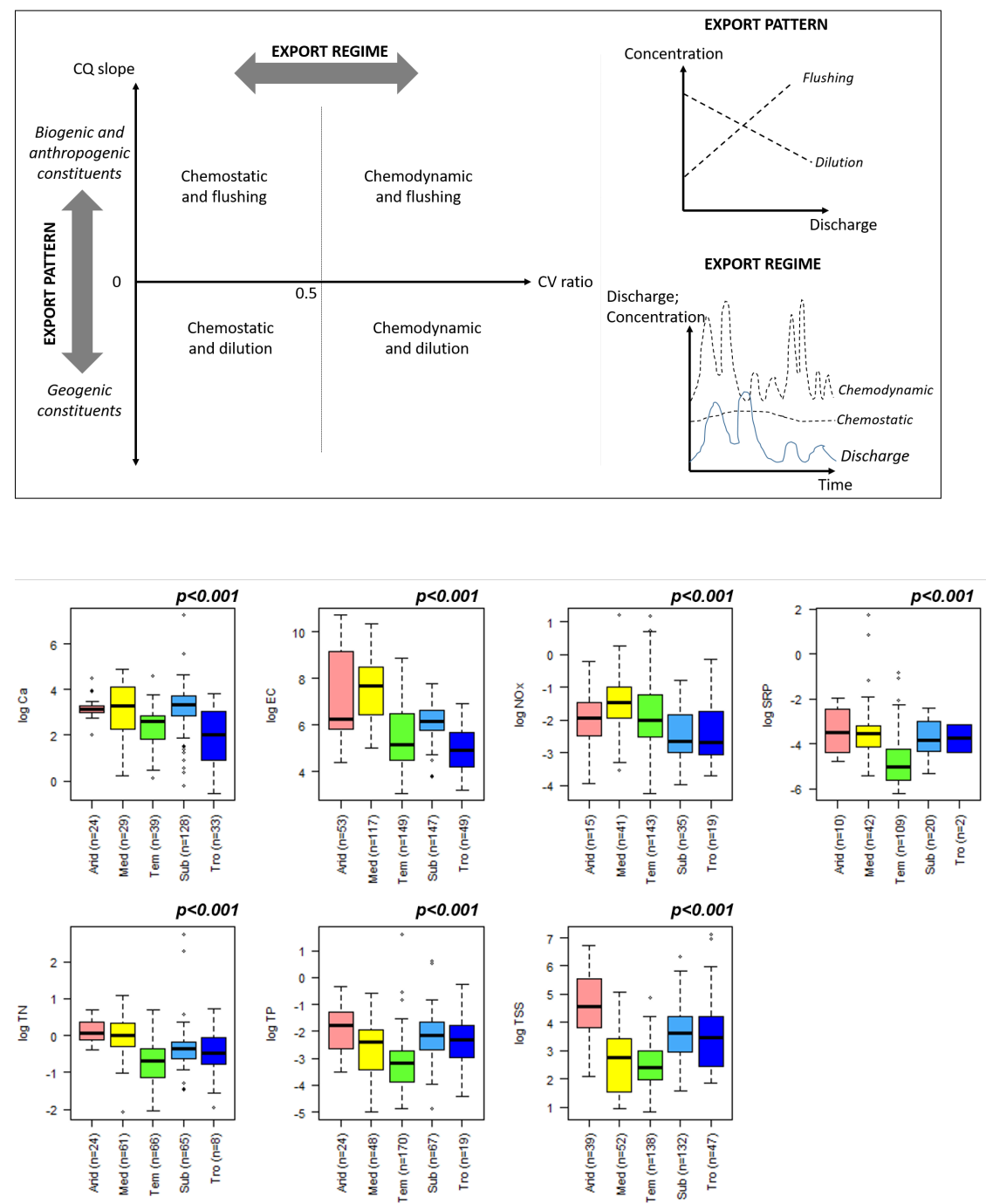


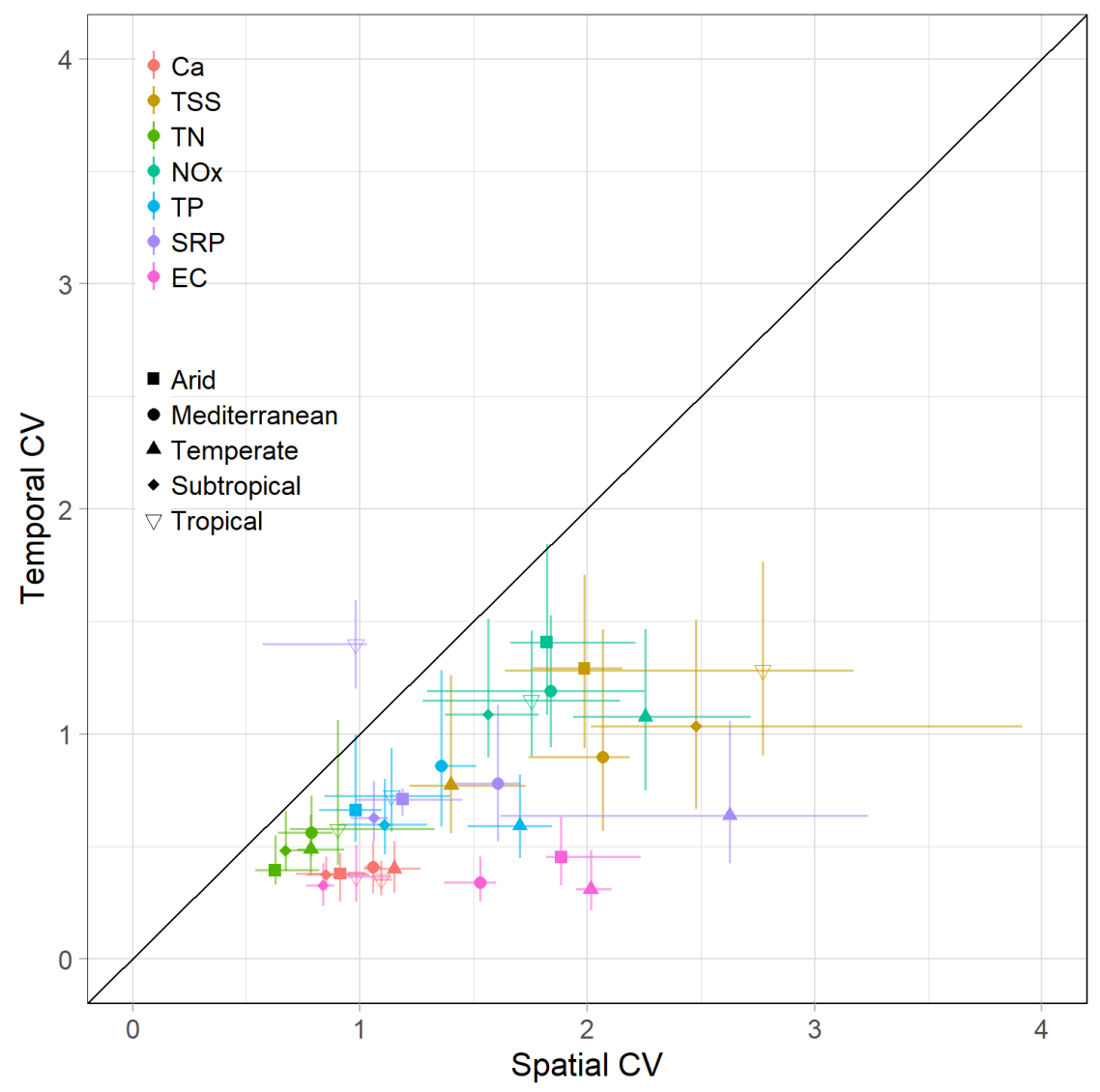

Select constituents $C Q$ slope vs $C V$ ratio
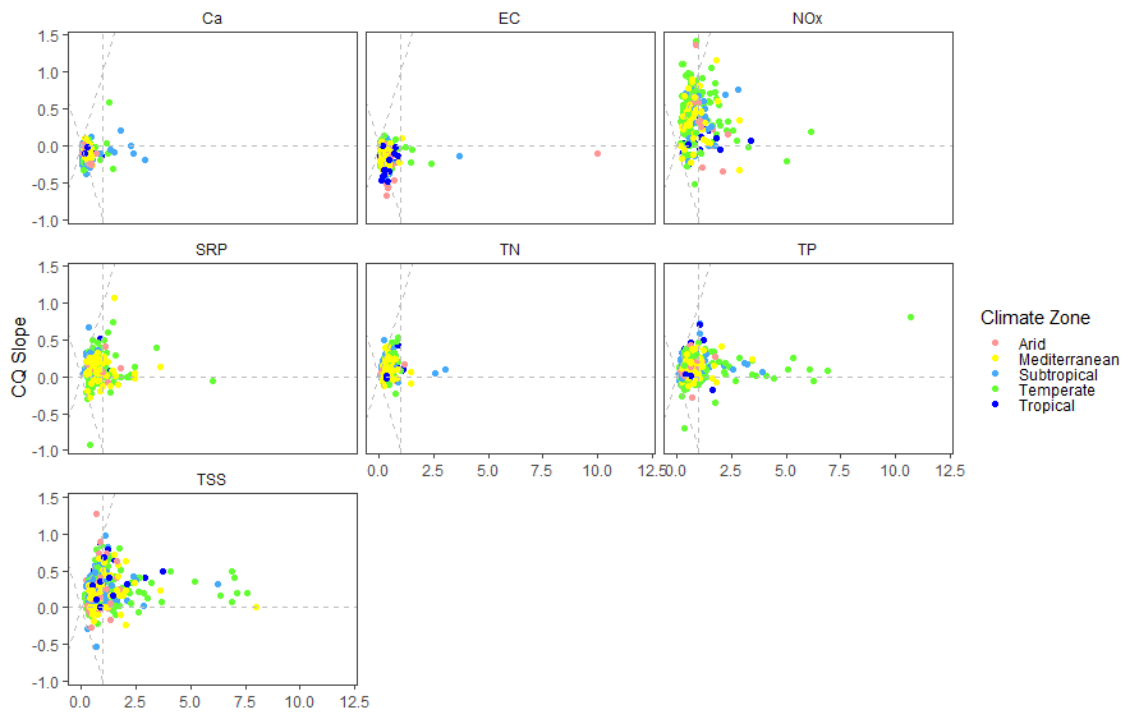

CV ratio 

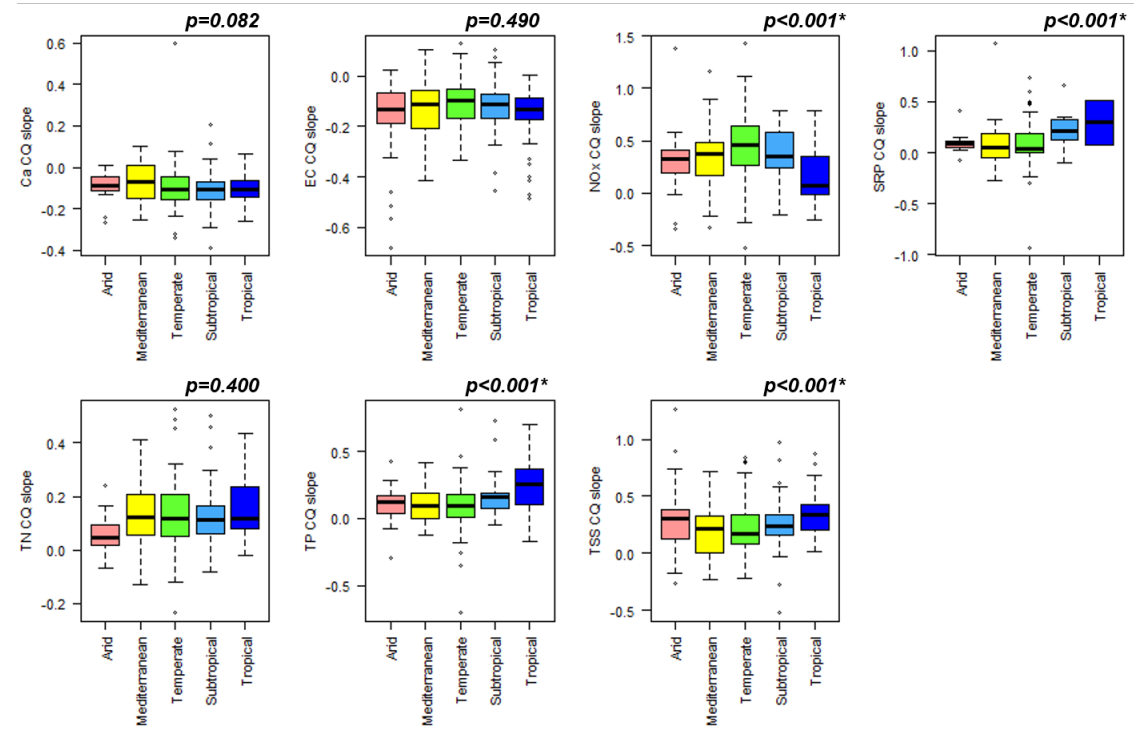